\title{
Hubungan Penggunaan Gadget Dengan Kemandirian Dan Kematangan Sosial Anak Pra Sekolah
}

\author{
The Relationship Between Use Of Gadgets With The Independence And \\ Social Maturity Of Preschoolers
}

\author{
Tutik Hidayati ${ }^{1}$, Yessy Nur Endah Sary,Iis Hanifah \\ STIKES Hafshawaty Pesantren Zainul Hasan \\ ${ }^{1}$ Email: afithuafda2702@gmail.com
}

\begin{abstract}
ABSTRAK
Perkembangan anak dapat dilakukan dengan kebiasaan lingkungan dan pemberian stimulasi pada anak pra sekolah. Penggunaan gagdet mempunyai dampak yang besar, baik dampak baik maupun buruk untuk semua orang, terutama bagi anak pra sekolah dengan perkembangan teknologi pada saat ini. Anak pra sekolah dengan gangguan perkembangan sebanyak 85.779 (62,02\%). Selain itu anak pra sekolah juga mengalami masalah emosional yang berdampak negatif pada perkembangan dan kesiapan untuk bersekolah sekitar 9,5\% - 14,2\% anak berusia antara nol sampai lima tahun. Tujuan penelitian ini adalah untuk menganalisis Hubungan Penggunaan Gadget Dengan Kemandirian Dan Kematangan Sosial Anak di TK Putra Bangsa Kecamatan Gading. Desain penelitian yang digunakan adalah cross sectional. Pengumpulan data yang digunakan pada penelitian ini menggunakan kuesioner. Hasil uji Spearman Rank antara penggunaan gagdet dengan kemandirian dan kematangan sosial diperoleh nilai $\mathrm{p}$ value $0,000<\alpha$ 0,05, maka ha diterima sehingga ada hubungan antara penggunaan gagdet dengan kemandirian dan kematangan sosial.. Besarnya nilai Exp (B) pada analisis regresi logistik kemandirian memiliki nilai 4,668 yang berarti bahwa kemandirian memiliki peluang 4,668 kali untuk berubah. Sedangkan variabel kematangan sosial pada regresi logistik berganda memiliki nilai Exp (B) sebesar 2,545, dari hasil tersebut dapat dijelaskan bahwa kematangan sosial memiliki peluang meningkat 2,545kali.
\end{abstract}

Kata kunci: Gadget, Kemandirian, Kematangan Sosial, Anak Pra Sekolah.

\begin{abstract}
Child development can be done with environmental habits and the provision of stimulation to pre-school children. The use of gagdet has a large impact, both good and bad for everyone, especially for preschoolers with technological developments at this time. Preschool children with developmental disorders were 85,779 (62.02\%). Besides pre-school children also experience emotional problems that have a negative impact on the development and readiness to go to school around 9.5\% - $14.2 \%$ of children aged between zero to five years. The purpose of this study was to analyze the Relationship between the Use of Gadgets and the Independence and Social Maturity of Children in Putra Bangsa Kindergarten, Gading District. The research design used was cross sectional. Data collection used in this study using a questionnaire. Spearman Rank test results between the use of gagdet with independence and social maturity obtained $p$ value $0,000<\alpha 0.05$, then ha is accepted so that there is a relationship between the use of gagdet with independence and social maturity. has a value of 4.668 which means that independence has a 4,668 chance to change. While the social maturity variable in multiple logistic regression has an $\operatorname{Exp}(B)$ value of 2.545, from these results it can be explained that social maturity has an opportunity to increase by 2.545 times. .
\end{abstract}

Keywords: Gadgets, Independence, Social Maturity, Preschool Children 


\section{PENDAHULUAN}

Masa prasekolah merupakan periode penting dalam proses tumbuh kembang manusia. Perkembangan sosial dan emosianal anak prasekolah adalah perolehan kemampuan berperilaku sesuai dengan tuntutan sosial pada suatu keadaan yang terangsang dari organisme mencakup perubahan perubahan yang disadari, yang mendalam sifatnya dari perubahan perilaku saat berusia 3-6 tahun. Kemampuan sosial dan emosional merupakan fondasi bagi perkembangan kemampuan anak berinteraksi dengan lingkungannya secara lebih luas. Dalam berinteraksi dengan orang lain, individu tidak hanya dituntut untuk mampu berinteraksi secara baik dengan orang lain, tetapi terkait juga didalamnya bagaimana ia mampu mengendalikan dirinya secara baik. Keberhasilan masa sekarang menentukan Perkembangan dan pertumbuhan yang akan datang. Setiap anak tumbuh kembangnya berbeda satu dengan yang lain. Hal ini disebabkan banyak faktor selama tumbuh kembang anak berlangsung. (Supartini, 2009). Perkembangan anak dapat dibentuk dengan kebiasaan lingkungan dan pemberian stimulasi terhadap anak prasekolah. Penggunaan gagdet merupakan salah satu berkembangnya teknologi yang berpengaruh pada anak.

Perkembangan teknologi dan informasi mengalami kemajuan yang sangatpesat yang ditandai dengan kemajuan pada bidan informasi dan teknologi. (Ismanto, 2015).Salah satu yang menjadi perkembangan gagdet yaitu semakin meluasnya, hampir semua individu baik anak-anak hinggaorang dewasa kini sudah memiliki handphone atau smartphone. Kebutuhan informasi dan komunikasi sangat dibutuhkan bagi semua kalangan masyarakat, ditambah sekarang semakin mudah mengakses informasidan berbagai macam fitur menarik yang menawarkan oleh jasa pelayanan gagdet itu sendiri sehingga anak-anak sering kali cepat akrab dengannya. Pada anak usia 5 tahun bole- boleh saja diberi gagdet, tapi harus diperhatikan durasi pemakaiananya, misalkan boleh bermain hanya setengah jam atau pada saat senggang. Penggunaan gagdet akan memberikan dampak yg buruk bagi perkembangan sosial dan emosional anak apabila penggunaanya berlebih. Dampak buruk gagdet pada anak tersebut antara lain anak menjadi pribadi tertutup, gangguan tidur, suka 
menyendiri, perilaku kekerasan, pudarnya kreativitas, dan ancaman cyberbullying (Iswidharmanjaya, 2014). Berdasarkan data dari World Health Organitation (WHO) bahwa anak prasekolah mengalami ganggguan perkembangan yaitu disfungsi otak minor sebanyak 5-25\% (Widati, 2012). Departemen Kesehatan RI Dalam Widati (2012), Di Indonesia balita yang mengalami gangguan perkembangan motorik halus dan kasar, , pendengaran, sosial dan emosional, dan keterlambatan bicara sebanyak 0,4 juta (16\%).

Sedangkan menurut Dinas Kesehatan Jawa Tengah dalam Widati (2012), usianak prasekolah mengalami gangguan perkembangan sebesar 85.779 (62,02\%) (Widati, 2012). Selanjutnya menurut Widawati tahun 2012 menyatakan bahwa anak megalami gangguan masalah sosial emosional sekitar 9,5\% - 14,2\% berusia berusia antara nol sampai lima tahun yang berdapak pada fungsi perkembangan dan kesiapan bersekolah.

Sebuah penelitian dikeluarkan oleh American Association of Pediatrics (AAP) dengan tajuk "penggunaan media menjadi dominan dalam kehidupan anak-anak zaman sekarang”. Media yang paling umum digunakan anak adalah gadget, dalam kurun waktu dua tahun penggunaan gagdet meningkat dua kali lipat dari $38 \%$ menjadi $72 \%$ yaitu antara 2011 dan 2013 (Uhls, 2016). Orang tua memperbolehkan anaknya untuk menggunakan gagdet lebih dari 1 jam sebanyak $98 \%$ berdasarkan survei yang dilakukan oleh The Asian Parent Insight bersama Samsung Kidstime melalui Mobile Device Usage Among Young Kids pada awal tahun 2014.

Hasil penelitian yang dilakukan kepada beberapa keluarga di wilayah Yogyakarta pada tahun 2013, banyak dampak buruk dari penggunaan gagdet diantaranaya ketika dirumah anak menjadi susah diajak berkomunikasi, tidak peduli dan kurang berespon pada saat orang tua mengajaknya berbicara (Anggrahini, 2013). Hal tersebut akan menganggu perkembangan sosial dan emosional pada anak apabila hal ini berlangsung terus menerus,anak-anak seharusnya berinterkasi dengan lingkungan sekitar tetapi dengan adanya gadget sebuah interaksi tersebut akan mengalami sebuah gangguan.

$$
\text { Setelah dilakukan survey }
$$
pendahuluan pada tanggal 9 Desember 2018 Di TK Putra Bangsa Desa Gading terhadap 10 orang tua wali murid dan 
10 anak dengan wawancara. Dari hasil survey didapatkan bahwa, dari 10 murid yang terpapar Gadget ada 9 (90\%) dengan lama paparan 30 menit- 6 jam/hari, sedangkan yang tidak terpapar gadget $1(10 \%)$ murid.

Menurut Efendi (2013), hal yang paling berpengaruh dalam mencegah maupun mengatasi dampak negatif dari gadget adalah orang tua. Agar gagdet tidak berdampak buruk bagi anak makaorang tua harus memiliki peran besar dalam membimbing dan mencegah. Pengenalan dan penggunaan gadget, batasi waktu dalam penggunaan gadget, hindarkan kecanduan, dan beradaptasi dengan zaman merupakan hal-hal yang bisa dilakukan orang tua.

Tujuan penelitian ini yaitu untuk mengetahui hubungan Penggunaan Gadget Dengan kemandirian pada anak TK Putra Bangsa Desa Gading, mengetahui hubungan Penggunaan Gadget Dengan kematangan sosial pada anak TK Putra Bangsa Desa Gading dan untuk menganalisis Hubungan Penggunaan Gadget Terhadap Kemandirian Dan Kematangan Sosial Anak Di TK Putra Bangsa Desa Gading

\section{METODE PENELITIAN}

Desain penelitian yang digunakan adalah cross sectional. Populasi pada penelitian ini yaitu semua ibu yang mempunyai anak prasekolah di Di TK Putra Bangsa sebanyak 90 orang. Sampling: Menggunakan Total Sampling. Untuk mengukur penggunaan gadget, kemandirian dan kematangan sosial menggunakan kuesioner. Analisis Data pada penelitian ini yaitu analisis Univariat menggunakan distribusi frekuensi. Analisis Bivariat menggunakan Spearman Rank. Analisis Multivariat menggunakan regresi logistik berganda.

\section{HASIL DAN PEMBAHASAN}

Dalam data umum ini disajikan mengenai data umum dari sampel penelitian hubungan penggunaan gagdet dengan kemandirian dan kematangan sosial anak. Data umum tersebut antara lain berupa jenis kelamin, usia anak, pendidikan ibu,pekerjan ibu.

Table 1. Distribusi Responden Berdasarkan Jenis Kelamin Anak.

\begin{tabular}{cccc}
\hline No & $\begin{array}{c}\text { Jenis } \\
\text { Kelamin }\end{array}$ & Frekuensi & Persentase \\
\hline 1 & Laki-laki & 46 & 51,1 \\
2 & Perempuan & 44 & 48,9 \\
& Total & 90 & 100,0 \\
\hline
\end{tabular}


Berdasarkan tabel 1. sebagian besar anak adalah berjenis kelamin lakilaki yaitu sebanyak 46 orang $(51,1 \%)$.

Berdasarkan tabel 3. mayoritas

Tabel 2. Distribusi Responden Berdasarkan Usia Anak.

\begin{tabular}{cccc}
\hline No & $\begin{array}{c}\text { Usia } \\
\text { Anak }\end{array}$ & Frekuensi & Persentase \\
\hline 1 & 4 Tahun & 19 & 21,1 \\
2 & 5 Tahun & 21 & 23,3 \\
3 & 6 Tahun & 50 & 55,6 \\
& Total & 90 & 100,0 \\
\hline
\end{tabular}

Berdasarkan tabel 2. mayoritas anak adalah berusia 6 tahun yaitu sebanyak 50 orang $(55,6 \%)$.

Tabel 3. Distribusi Responden Berdasarkan Pendidikan Ibu.

\begin{tabular}{clcc}
\hline No & $\begin{array}{c}\text { Pendidikan } \\
\text { Ibu }\end{array}$ & Frekuensi & Persentase \\
\hline 1 & SD & 48 & 53,3 \\
2 & SMP & 17 & 18,9 \\
3 & SMA & 18 & 20,0 \\
4 & Sarjana & 7 & 7,8 \\
& Total & 90 & 100,0 \\
\hline
\end{tabular}
ibu yang mempunyai anak yang menjadi sampel dalam penelitian adalah berpendidikan SD yaitu sebanyak 48 orang $(53,3 \%)$.

Tabel 4. Distribusi Responden Berdasarkan Pekerjaan Ibu.

\begin{tabular}{cccc}
\hline \multirow{2}{*}{ No } & $\begin{array}{c}\text { Pekerjaan } \\
\text { Ibu }\end{array}$ & Frekuensi & Persentase \\
\hline 1 & IRT & 66 & 73,3 \\
2 & Swasta & 17 & 18,9 \\
3 & Guru & 7 & 7,8 \\
& Total & 90 & 100,0 \\
\hline
\end{tabular}

Berdasarkan tabel 4. mayoritas ibu yang mempunyai anak yang menjadi sampel dalam penelitian ini adalah IRT yaitu sebanyak 66 orang $(73,3 \%)$.

Tabel 5. Tabulasi Silang Penggunaan Gadget dengan Kemandirian Anak di TK Putra Bangsa Desa Gading.

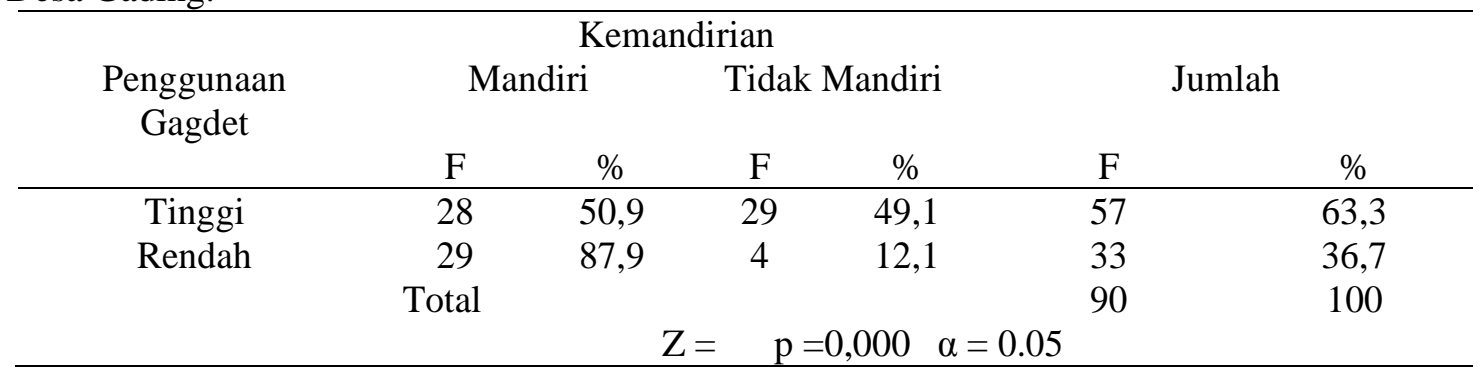


Berdasarkan tabel 5. radiasi, nyeri leher dan perubahan Berdasarkan di atas diketahui bahwa penggunan gadget pada responden tinggi dan tidak mandiri sebanyak 29 orang $(49,1 \%)$.

Hasil uji Spearman Rank antara penggunaan gagdet dengan kemandirian anak diperoleh nilai $\mathrm{p}$ value $0,000<\alpha 0,05$, maka ha diterima sehingga ada Hubungan penggunaan gagdet dengan kemandirian anak. Berdasarkan di atas diketahui bahwa penggunan gadget pada responden tinggi dan tidak mandiri sebanyak 29 orang $(49,1 \%)$.

Maraknya penggunaan gadget disebabkan oleh banyak faktor determinan . Faktor dominan penyebab pemaikan gadget yang tinggi di kalangan anak usia dini yaitu karena mayoritas orang tua berpikir dengan memberikan anaknya sebuah gadget anak bisa menjadi penurut, tidak menangis lagi dan sebagai ajang untuk memamerkan anaknya bisa mengotakatik gadge. Orang tua selalu memberi anak gadget agar anak tidak menangis dan menganggu orang tua. Akan Tetapi orang tua tidak memikirkan dampak gadget kepada anak. Dampak penggunaan gadget yaitu menghambat kecerdasan emosional, risiko terpapar anatomi tulang, hambatan terhadap perkembangan, lambat memahami pelajaran, berisiko terhadap perkembangan psikologi anak, perubahan perilaku anak (Annisa, 2019).

Anak yang melakukan kegiatan tugas sendiri atau dengan sedikit bimbingan sesuan dengan perkembangan dan kemampuan anak merupakan kemandirian anak. Dengan anak mampu mengenal mana yang benar dan mana yang salah, tetapi juga mampu membedakan mana yang baik dan mana yang buruk adalah kemandirian pada anak. Di samping itu, anak juga bisa menerapkan terhadap hal-hal yang menjadi larangan atau yang dilarang, serta mengetahui dampak dari melanggar aturan. Anak yang mandiri akan melakukan tindakan sesuai dengan pertimbangan, percaya diri atas diri sendiri serta bisa mengontrol terhdp kehidupannya. Dengan adanya kemandirian mampu bisa mengekspresikan gagasannya dengan cara yang mudah dipahami dan secara emosional kegiatan yang dilakukannya dipertanggungjawabkan sendiri baik secara fisik, mental dan kreatif (Sa'diyah, 2017). 
Pendampingan dialogis orang tua sangat dibutuhkan dalam mengawasi setiap kegiatan anak dalam bermain gadget dan perlu batasan-batasan dalam mengakses fitur fitur tertentu. Orang tua harus lebih cerdas dari anaknya. Perlu adanya strategi khusus dalam mengurangi dan menghindari anak dalam pemakaian gadget. Pola kedisiplinan yang konsisten perlu diterapkan oleh para orang tua, apa saja yang boleh dan tidak boleh diakses agar anak terhindar dari pengaruh negatif pengggunaan gadget (Warisyah, 2015).

Tabel 6. Tabulasi Silang Penggunaan Gadget Dengan Kematangan Sosial Anak di TK Putra Bangsa Desa Gading.

\begin{tabular}{|c|c|c|c|c|c|c|c|c|}
\hline \multirow{2}{*}{$\begin{array}{c}\text { Penggunaan } \\
\text { Gagdet }\end{array}$} & \multicolumn{6}{|c|}{ Kematangan Sosial } & \multicolumn{2}{|c|}{ Jumlah } \\
\hline & $\mathrm{F}$ & $\%$ & $\mathrm{~F}$ & $\%$ & $\mathrm{~F}$ & $\%$ & $\mathrm{~F}$ & $\%$ \\
\hline Tinggi & 2 & 3,5 & 22 & 38,6 & 33 & 57,9 & 57 & 63,3 \\
\hline \multirow[t]{3}{*}{ Rendah } & 4 & 12,1 & 0 & 0 & 29 & 87,9 & 33 & 36,7 \\
\hline & \multicolumn{6}{|c|}{ Total } & 90 & 100 \\
\hline & & & & $\mathrm{p}$ & 000 & $=0.05$ & & \\
\hline
\end{tabular}

Berdasarkan tabel 6. di atas diketahui bahwa penggunan gadget tinggi dengan kematangan sosial rendah pada responden tinggi sebanyak 33 orang $(57,9 \%)$.

\section{Hasil uji Spearman Rank} antara penggunaan gagdet dengan kemandirian anak diperoleh nilai $p$ value $0,000<\alpha 0,05$, maka ha diterima sehingga ada Hubungan penggunaan gagdet dengan kematangan sosial anak.

Berdasarkan di atas diketahui bahwa penggunan gadget tinggi dengan kematangan sosial rendah pada responden tinggi sebanyak 33 orang $(57,9 \%)$.
Pada kondisi yang ideal dengan berkembang pesatnya gadget di Indonesia sebenarnya gadget digunakan untuk hal-hal yang bermanfaat. Penggunaan gadget dengan sebaik-baiknya seharusnya dapat mengedukasi, tidak hanya menjadi bangsa pasar, akan tetapi bisa digunakan untuk menaikan sumber daya manusia, baik untuk kepentingan pendidikan, bisnis maupun kepentingan lainnya. Gadget tidak hanya digunakan untuk kepentingan hiburan semata, dengan Indonesia dijadikan bangsa pasar sebaiknya gadget digunakan pada hal yang tepat, sasaran yang tepat dengan begitu perkembangan gadget 
dapat menaikan sumber daya manusia Indonesia (Warisyah, 2015).

Pengasuhan yang tepat dari orang tua sangatlah penting diberikan kepada anak, karena anak masih terlalu muda dan belum memiliki pengalaman untuk membimbing perkembangannya sendiri ke arah kematangan. Arahan serta bimbingan orangtua menjadi kunci keberhasilan anak untuk dapat membentuk kepribadian yang mandiri dan kompeten secara sosial (Viandari, 2019).

Anak yang terlalu fokus pada gadget akan mempengaruhi perkembangan sosial anak untuk beradaptasi dengan orang lain. Perkembangan sosial mengikuti suatu pola, yaitu suatu urutan perilaku sosial. Pola ini sama pada semua anak di dalam suatu kelompok budaya. Pola sikap anak yang berhubungan dengan minat adalah aktivitas sosial dan pilihan teman. Generasi penerus bangsa yakni anakanak telah di rusak oleh zaman modern saat ini dan menimbulkan generasi tidak baik untuk bangsa ini. Hal ini harus di antisipasi oleh orang tua agar anak-anak tidak lagi kecanduan dengan gadget dan berikan anak peraturan bermain serta jadwal yang tepat dalam penggunaan gadget sehingga sangat perlu didampingi oleh orang tua agar perkembangan sosial anak tidalagi dirampas oleh gadget tersebut. (Annisa, 2019).

Perkembangan sosial anak akan berkembang dengan baik jika lingkungan di sekitarnya seperti di sekolah, rumah maupun di lingkungan bermainnya mendukung untuk tetap beraktifitas fisik. Sehingga dengan demikian aktifitas dengan menggunakan gadget dapat terlupakan. Hal ini bisa dicapai jika komponen yang terkait dengan siswa seperti orang tua dan teman-teman mampu untuk membuat kegiatan fisik di lingkungan anak tersebut.

Tabel 7. Analisis Regresi Logistik Berganda Antara Penggunaan Gagdet Terhadap Kemandirian dan Kematangan Sosial Anak.

\begin{tabular}{lcll}
\hline \multicolumn{1}{c}{ Variabel } & Sig & \multicolumn{1}{c}{$\operatorname{Exp~(B)~}$} & \multicolumn{1}{c}{ CI (95\%) } \\
\hline Kemandirian & 0,039 & 4,668 & $0,546-39,941$ \\
$\begin{array}{l}\text { Kematangan } \\
\text { Sosial }\end{array}$ & 0,043 & 2,545 & $0,058-1,648$ \\
\hline \multicolumn{5}{c}{ Berdasarkan } & tabel & 7. & dapat
\end{tabular}
dipahami bahwa pola asuh makan memiliki nilai sig $0,039<0,05$ yang berarti ada hubungan antara pengguna gagdet dengan kemandirian. Penggunaan gagdet memiliki nilai sig $0,043<0,05$ yang berarti ada hubungan antara penggunaan gagdet dengan kematagan sosial anak. 
Besarnya nilai Exp (B) pada analisis regresi logistik kemandirian memiliki nilai 4,668 yang berarti bahwa kemandirian memiliki peluang 4,668 kali untuk berubah. Sedangkan variabel kematangan sosial pada regresi logistik berganda memiliki nilai Exp (B) sebesar 2,545, dari hasil tersebut dapat dijelaskan bahwa kematangan sosial memiliki peluang meningkat 2,545kali.

Berdasarkan tabel diatas dapat dipahami bahwa pola asuh makan memiliki nilai sig 0,039<0,05 yang berarti ada hubungan antara pengguna gagdet dengan kemandirian. Penggunaan gagdet memiliki nilai sig $0,043<0,05$ yang berarti ada hubungan antara penggunaan gagdet dengan kematagan sosial anak

$$
\text { Besarnya nilai Exp (B) pada }
$$
analisis regresi logistik kemandirian memiliki nilai 4,668 yang berarti bahwa kemandirian memiliki peluang 4,668 kali untuk berubah. Sedangkan variabel kematangan sosial pada regresi logistik berganda memiliki nilai Exp (B) sebesar 2,545, dari hasil tersebut dapat dijelaskan bahwa kematangan sosial memiliki peluang meningkat 2,545kali.

Idealnya seorang anak usia dini yang berada pada masa prasekolah memerlukan kemampuan interaksi sosial yang baik agar dapat menyesuaikan diri dan mengembangkan diri secara optimal. Pada kenyataannya, tidak semua anak mampu berinteraksi sosial dengan baik, karena setiap anak memiliki kesiapan fisik dan mental yang beragam untuk menyesuaikan diri dengan lingkungannya, sehingga ada kalanya anak-anak memiliki hambatan selama proses pengembangan diri pada masa prasekolah. Salah satu faktor yang memengaruhi interaksi sosial anak adalah pola asuh orangtua. Bimbingan orangtua terhadap anak dalam berbagai aspek kehidupan sosial, atau normanorma kehidupan bermasyarakat serta mendorong dan memberikan contoh kepada anak bagaimana menerapkan norma-norma ini dalam kehidupan sehari-hari merupakan faktor-faktor yang mempengaruhi perkembangan sosial anak (Viandari, 2019).

Dalam bermain gadget perlu batasan-batasan dalam mengakses fitur fitur tertentu serta pengawasan dari orang tua. Orang tua harus lebih cerdas dari anaknya. Perlu adanya strategi khusus dalam mengurangi dan menghindari anak dalam pemakaian gadget. Pola kedisiplinan yang 
konsisten perlu diterapkan oleh para orang tua, apa saja yang boleh dan tidak boleh diakses agar anak terhindar dari pengaruh negatif pengggunaan gadget (Warisyah, 2015).

\section{Penggunaan gadget yang} bijaksana akan memberikan dampak positif bagi perkembangan sosial anak di usia dini dalam pertumbuhannya. Orang tua sangat berperan vital mendampingi buah hati saat menggunakan smartphone. Bilaor ang tua telah berhasil membuat kesepakatan dengan anak tentang peraturan bermain smartphone, kemudian bisa membuat jadwal harian, menentukan jam boleh bermain smartphonedan seterusnya, maka inilah saat yang aman untuk menggunakan gawai atau gadget (Annisa, 2019).

Belajar dari fenomena yang ada sebaiknya lembaga yang memiliki wewenang dan sebagainya sebaiknya memberikan parenting education atau sosialisasi kepada orang tua mengenai dampak penggunaan gadget. Sehingga orang tua mengetahui dampak smartphone terhadap perkembangan anak dan bagaimana seharusnya orang tua memberikan smartphone kepada anak usia dini. Apabila orang tua mendampingi, mendidik, mengajarkan dan membuatkan peraturan dalam menggunakan smartphone pada anak, maka perkembangan sosial anak akan berkembangan dengan baik.Lembaga yang memiliki wewenang sebaiknya juga melakukan kegiatan seminar untuk para orang tua mengenai dampak gadget terhadap anak. Selain itu menjelaskan kegiatan fisik yang sebaiknya dilakukan (Annisa, 2019).

Anak yang bersekolah di TK Putra Bangsa Gading Wetan masih belum mampu untuk mandiri karena telah dipengaruhi oleh faktor eksternal yang lebih dominan daripada faktor internal yaitu terpapar oleh lingkungan dimana sebagian besar teman mereka telah menggunakan gadget untuk menonton video anak-anak, sekedar untuk bermain games dan sebagainya. Selain teman di sekitar rumah dan sekolah, anggota keluarga meraka juga menggunakan gadget sehingga anakanak secara tidak langsung meniru perilaku dari anggota keluarga tesebut.

Perkembangan sosial anak akan berkembang dengan baik jika lingkungan di sekitarnya seperti di sekolah, rumah maupun di lingkungan bermainnya mendukung untuk tetap beraktifitas fisik. Sehingga dengan 
demikian aktifitas dengan menggunakan gadget dapat terlupakan. Hal ini bisa dicapai jika komponen yang terkait dengan siswa seperti orang tua dan teman-teman mampu untuk membuat kegiatan fisik di lingkungan anak tersebut.

\section{SIMPULAN DAN SARAN}

Penggunan gadget pada responden tinggi dan tidak mandiri sebanyak 29 orang $(49,1 \%)$. Penggunan gadget tinggi dengan kematangan sosial rendah pada responden tinggi sebanyak 33 orang $(57,9 \%)$. Besarnya nilai $\operatorname{Exp}$ (B) pada analisis regresi logistik kemandirian memiliki nilai 4,668 yang berarti bahwa kemandirian memiliki peluang 4,668 kali untuk berubah. Sedangkan variabel kematangan sosial pada regresi logistik berganda memiliki nilai Exp (B) sebesar 2,545, dari hasil tersebut dapat dijelaskan bahwa kematangan sosial memiliki peluang meningkat 2,545kali.

Diharapkan orang tua agar membatasi pemberian bermain gagdet dalam frekuensi jarang atau tidak boleh bermain lebih dari 1 jam perhari dan mengawasi anak dalam menggunakan fitur gagdet agar tidak berdampak negatif pada anak.

\section{DAFTAR PUSTAKA}

Affrida. 2017. Strategi Ibu Dengan Peran Ganda Dalam Membentuk Kepribadian Anak Usia Pra Sekolah. Jurnal Obsesi. Vol.1 No. 2

Anggraini, 2013. Persepsi Terhadap Anak Berkebutuhan Khusus. Jurnal Ilmiah Pendidikan Khusus. Volume 1, Januari 2013, 258-264.

Annisa. 2019. Hubungan Persepsi Orang Tua Tentang Dampak SmartphoneTerhadap Perkembangan Sosial Pada Anak Di Kelompok Bermain Gugus I Kecamatan Nanggalo Kota Padang. Jurnal Ilmiah Potensia. Vol. 4 (1).

Astuti. 2013. Implementasi Program Fullday School Sebagai Usaha Mendorong Perkembangan Sosial Peserta Didik TK Unggulan Al Ya'lu Kota Malang. Jurnal Kebijakan Dan Pengambangan Pendidikan. Vol.1 No.2.

Efendi, Fuad. 2013. Pengarug Gadget Terhadap Perkembangan Anak Usia Dini. Skripsi. Teknik Informatika Universitas Brawijaya. Iswidharmanjaya, Derry \& Agency, Beranda. 2014. Bila Si Kecil Bermain Gadget: Panduan Bagi Orang Tua Untuk Memahami Faktor-faktor Penyebab Anak Kecanduan Gadget. Yogyakarta: Bisakimia.

Sa'diyah. 2017. Pentingnya Melatih Kemandirian Anak. Jurnal Kordinat. Vol. XVI No. 1.

Viandari. 2019.Peran pola asuh orangtua dan penggunaan gadget terhadap interaksi sosial anak prasekolah. Jurnal Psikologi Udayana. Vol.6, No.2.

Warisyah. 2015. Pentingnya Pendampingan Dialogis Orang Tua Dalam Penggunaan Gadget Pada 
118 Oksitosin: Jurnal Ilmiah Kebidanan, Vol. 6, No. 2, Agustus 2019 : 107-118

Anak Usia Dini. Prosiding Seminar Nasional Pendidikan.

Widati, Tri. 2012. Meningkatkan Kemampuan Motorik Halus Anak Melalui Metode Melipat Kertas pada Anak Kelompok B TK ABA Gani Socokangsi Jatinom Klate 